\title{
Home on the Digital Range: Ranchers' Web Access and Use
}

\author{
Shayan Ghajar ${ }^{\text {a,*}}$, María E. Fernández-Giménez ${ }^{\mathrm{b}}$, Hailey Wilmer ${ }^{\mathrm{c}}$ \\ a Department of Crop \&' Soil Environmental Sciences, Virginia Polytechnic Institute and State University, Middleburg, VA 20117, USA \\ ${ }^{\mathrm{b}}$ Department of Forest and Rangeland Stewardship, Colorado State University, Fort Collins, CO 80523-1472, USA \\ ${ }^{c}$ US Department of Agriculture (USDA) Northern Plains Climate Hub, USDA - Agricultural Research Service Rangeland Resources and Systems Research Unit, Fort Collins, CO 80526, USA
}

\section{A R T I C L E I N F O}

\section{Article history:}

Received 14 March 2018

Received in revised form 19 September 2018

Accepted 22 December 2018

\section{Key Words:}

cluster analysis

decision making

mixed methods

online Extension

rancher survey

\begin{abstract}
A B S T R A C T
Access to the Internet continues to grow in rural areas, ensuring ranchers will have increasing opportunities to use the Web to find information about management practices that may provide them ecological and financial benefits. Although past studies have examined the role of the Internet in informing daily decision making by agricultural producers, no studies have focused specifically on the use of the Internet by ranchers in the western United States. This study uses a mixed-methods approach (a survey and semistructured interviews) to assess the extent and patterns of ranchers' Internet use in Colorado and Wyoming, identify barriers to greater use, and establish a typology of Web use behavior by ranchers. Our findings indicate that Internet use is widespread and that age, education, and risk tolerance predict the extent to which a rancher will rely on the Internet for dayto-day ranch management. A cluster analysis delineated four distinct types of Web usage among ranchers: uninfluenced, focused on sales and herd management, moderately influenced, and an Internet-reliant type. Outreach personnel can use this classification to determine the potential utility of digital outreach tools for their programming on the basis of their target audience and outreach topics.
\end{abstract}

(c) 2018 Published by Elsevier Inc. on behalf of The Society for Range Management.

\section{Introduction}

The Internet is "the most rapidly diffusing innovation in the history of mankind" (Rogers, 2001). While urban areas witness the fastest growth of internet use and availability, rural areas are also rapidly developing reliable access to the Internet (DiMaggio and Hargittai, 2001). However, many rural areas have infrastructural deficits relative to urban areas that impact data connectivity (Salemink et al., 2017). In addition, some rural populations may have lower levels of digital skills and knowledge (Salemink et al., 2017), as well as fewer opportunities to develop these skills (Hodge et al., 2017).

A 2012 survey of ranchers in Wyoming found that 82\% of respondents had Internet access, with $75 \%$ of respondents reporting highspeed access (Kachergis et al., 2013). Moreover, 42\% of respondents reported using the Internet on a daily basis, with another $31 \%$ using it one or more times per week (Kachergis et al., 2013). Flexibility is key to management of rangeland systems, especially highly variable semiarid and arid systems. Instantaneous access to information on weather,

\footnotetext{
it This research was funded by a USDA National Institute of Food and Agriculture Invasive Species Program award titled "Ecological and Economic Risk Assessment Decision Tool for Management of Bromus tectorum Invasions (award 2008-55320-04570)" and the Colorado Agricultural Experiment Station.

* Correspondence: Shayan Ghajar, Dept of Crop \& Soil Environmental Sciences, Virginia Polytechnic Institute and State University, Middleburg, VA, 20117, USA. Tel.: +1 703967 3662.

E-mail address: sghajar@vt.edu (S. Ghajar).
}

climate, market conditions, or social and political events could impact rancher decision making on multiple scales, as it already has for pastoralists in Asia and Africa (Waters-Bayer and Bayer, 2016). In addition, enhanced connectivity to social networks offered by the Internet may appeal to ranchers, as maintaining and building social networks is essential to community well-being in rural areas (Tickamyer et al., 2017). The near-ubiquity of the Internet, as well as the relative ease with which users can find information online, ensures it will play a significant role in the future of natural resources and Extension educational outreach (King and Boehlje, 2000; High and Jacobson, 2005).

As a result of this expanding potential to use the Internet as a medium for range Extension and outreach provided by state and federal agency employees or private consultants, myriad websites addressing issues relating to rangeland management have been developed. Sites such as Rangelands West, the Range Science Information System, and eXtension offer free resources to Web surfers seeking information on rangeland systems (Hutchinson et al., 2011). A simple search on any popular search engine for terms such as "rangeland ecology" or "rangeland management" returns thousands of results. As Hutchinson and Ruyle (2006) point out, the issue facing Web users searching for range-related information is not its lack but rather sorting through the surplus to find information that is directly relevant to their questions and situation.

This study identifies and describes trends of Internet use by Colorado and Wyoming ranchers and evaluates the current and potential future use of the Internet as an outreach tool. Specifically, we document how 
many respondents used the Internet and how, as well as the biggest barriers to greater Internet use. Within the population of ranchers with Internet access in our sample, we determine the extent to which information gleaned from the Internet influenced ranchers' decision making both generally and in specific rangeland and ranch management areas. Finally, we identify patterns of individual use to determine the types of Web users outreach personnel may target for specific types of outreach activities.

\section{Innovation Diffusion}

The study of how new and potentially beneficial technologies or ideas spread is termed innovation diffusion. Innovation diffusion provides a framework for examining the processes by which ecologically beneficial tools and concepts may disseminate among ranchers. Everett Rogers, who has been described as the father of innovation diffusion research (McGrath and Zell, 2001), describes innovation diffusion as the process by which new ideas or technologies that are perceived as advantageous spread throughout a social system (Rogers, 2003).

To diffuse successfully, an innovation must have five primary attributes that demonstrate its advantage over previous systems: relative advantage, which is the perceived superiority of the innovation over other methods; compatibility with the technological, cultural, social, and economic system; a complexity not exceeding that of necessity; trialability, which is a term for the ease by which the innovation may be tested without major commitment; and observability of the superior outcomes of the innovation (Rogers, 2003).

The Internet is both an innovation and a medium by which innovations may be diffused. Rogers (2001) observes that the Internet possesses extremely high relative advantage over previous methods of communication, and he describes it as being one of the most quickly diffused inventions in the history of mankind. Following the initial costs and difficulty of obtaining Internet access, an individual may find more information than ever before with less effort than any other medium of information transfer (Rogers, 2001).

\section{Diffusion of Innovations among Ranchers}

Innovation diffusion among ranchers has received more study than Internet usage in the same sphere. Extant research has investigated the economic (and to a lesser extent, social and cultural) factors that correlate with adoption of specific innovations in ranching communities, though no connection as yet has been made theoretically or empirically between these innovations and Internet use.

Didier and Brunson (2004) studied innovation among Utah ranchers and carried out a meta-analysis of a number of studies into ranchers' tendency to innovate. The authors found that dependence on ranch income was an accurate predictor of innovativeness. Similarly, another study found that the potential of an innovation to increase income increased the likelihood of adoption (Rowan and White, 1994). Didier and Brunson (2004) developed specific predictors of likely innovators, finding that multigenerational ranchers, full-time ranchers, and ranchers who live on the ranch are all more likely to innovate. A more recent analysis of ranchers' participation in conservation programs found that larger operations were more likely to adopt the programs (Lubell et al., 2013). These findings appear to demonstrate a correlation among personal, financial, and familial ties to a ranch and increased likelihood of being an innovator or early adopter of innovative practices.

Certain factors also reduce the likelihood of the adoption of innovation. Financially disadvantaged ranches are less likely to overcome their risk aversion and therefore are less likely to innovate (Peterson and Coppock, 2001). Attachment to traditional methods of ranch management and operation, whether individual or community wide, is a significant cultural barrier to adoption of innovation (Grigsby, 1980). Didier and Brunson found that legal factors, such as fear of litigation, design of government programs, and public land regulations, were also substantial obstacles to innovative behavior (Didier and Brunson, 2004).

Kennedy (2005) and Kennedy and Brunson (2007) found a significant factor perhaps related to compatibility of an innovation: lifestyle preferences. Kennedy's, 2005 study of rancher innovations in Colorado found that preferences for a certain lifestyle by an individual rancher, or a ranching family as a whole, could strongly support or greatly weaken the desire to adopt a particular innovation. Although outreach efforts from the Colorado State University Extension were highly developed in the rancher communities of west-central Colorado, Kennedy and Brunson (2007) found that lifestyle preferences often ultimately determined whether or not Extension-endorsed innovations were adopted.

A study of adoption of innovations by ranchers in Colorado and Wyoming-upon which this survey is largely based-found that risk tolerance significantly predicted the implementation of innovative management practices by ranchers on their operations (Kelley, 2010). The study findings also showed that younger ranchers, those with more education, and ranchers with higher gross annual income were more likely to adopt innovations (Kelley, 2010). Ranchers' attitudes toward specific innovations were more likely to be positive if the innovations increased their grazing capacity, reduced the undesirable species on their property, or offered a direct financial gain (Kelley, 2010).

\section{Diffusion of the Internet and Its Use by Agricultural Producers}

As an innovation, the Internet possesses many qualities that promote its use and diffusion in rural communities, such as its high degree of relative advantage over previous methods of communication or gathering information. Following the initial costs and difficulty of obtaining Internet access, an individual may find more information than ever before with less effort than any other medium of information transfer (Rogers, 2001).

To use the Internet effectively to encourage ranchers to adopt ecologically and economically beneficial innovations, we need to know more about how ranchers use the Internet. Though general data exist from the US Agricultural Census quantifying the number of agricultural producers with Internet access (Supplement A, available online at https://doi.org/10.1016/j.rama.2018.12.009, USDA NASS, 2012), we have located no data to describe how online information sources influence ranchers' decision making in our study area. The most analogous data available concerns general farming and agribusiness with no specific information on ranching; however, ranching differs from other agricultural systems in its dependence on extensive native rangelandsmuch of which is publicly owned-rather than intensive improved pasture systems. Despite these differences in production methods and constraints, it is not known if and how ranchers' Internet use may differ from other agricultural producers' use. Gaining an understanding of ranchers' preferred uses of the Internet may prove critical to determining how to increase access to and use of rangeland management tools, as well as multidirectional exchange of knowledge within the rangeland management community.

Research by Mishra and Park (2005), including analysis of US Department of Agriculture statistics on farmers' Internet use, found that American farmers used the Internet for nine primary reasons. In descending order of importance, farmers used the Internet to track input and commodity prices; obtain information from a nonspecific variety of sources; obtain information specifically from the US Department of Agriculture; communicate with other producers; keep farm records; communicate with advisory services; use online banking; pay bills; and secure loans. Another survey conducted by Extension in Iowa quantified types of Internet use by farmers with Internet access (Arbuckle et al., 2011). The results indicate high levels of use for obtaining information on management practices, indicating that some agricultural producers actively seek innovations online. 


\section{Information Foraging Theory}

Accessibility is essential to the efficacy of Web-based outreach. Information-foraging theory argues that individuals will try to maximize the utility of information they locate while striving to minimize the cost in time or effort in finding it (Pirolli and Card, 1999). Information-foraging theory is based on the optimal foraging theory of Stephens and Krebs (1987), which posits that an organism will expend more energy to find more nutritious food until a point of diminishing returns is reached. In a similar fashion, information-foraging theory suggests that a Web surfer will expend time and cognitive effort proportionate to the perception of the availability and worth of the information sought until a point of diminishing returns is reached (Pirolli, 2005). In practice, this means that if a site or grouping of websites has useful information but is difficult to navigate, an individual may simply resort to lower-quality information if it is more accessible and still perceived as useful, because information-seeking behavior is determined by a compromise between the perceived utility of information and the accessibility of the information. As such, the navigability of a website and accessibility of the information are critical to the website's efficacy in achieving outreach goals.

Work on information seeking online emphasized that "information seekers are likely to cope with the perceived costs of information search and overload by seeking strategies that minimize the cognitive effort and time" (Metzger et al., 2010). Consequently, although the Internet requires little effort to access information, the mental energy and time required to sort through information potentially limit its usefulness (Pirolli, 2005).

Although our review of the literature found previous studies addressing the use of the Internet by agricultural producers in general, we found no studies about the use of the Internet by Western rangeland-based livestock producers. This study seeks to address this knowledge gap to determine the potential for the Internet to be used as a tool for outreach aimed at ranchers. We assess and describe the scope and manner of Internet use by ranchers in six regions of Colorado and Wyoming, determine the characteristics of ranchers most likely to rely on the Internet as a source of information, and create a typology of rancher Web use among ranchers with Internet access.

We approached this study with five hypotheses about ranchers' patterns of Internet use, which are drawn from the literature.

Hypothesis 1. On the basis of studies of Internet use by agricultural producers in other regions (Mishra and Park, 2005; Arbuckle et al., 2011), we hypothesized that ranchers will report using the Internet most often for business-related purposes.

Hypothesis 2. Ranchers' wealth, operational scale (in acres of private land and animal units), risk tolerance, education, and age will be the best predictors of Internet use in the day-to-day management of their ranches. Past research has demonstrated these attributes are predictive of Internet use and/or the adoption of innovations (Rogers, 2001; Kennedy, 2005; Kennedy and Brunson, 2007; Kelley, 2010).

Hypothesis 3. Risk tolerance will act as a mediating variable among wealth, operational scale, education, and age for predicting the reliance of ranchers on the Internet for daily ranch management. This hypothesis is based on the results of Kelley's (2010) research, which identified risk tolerance as a mediating variable between demographic and operational attributes of a rancher and adoption of innovations.

Hypothesis 4. In accordance with information foraging theory (Pirolli, 2005), we hypothesize that lack of time to find information online and lack of trust in Web-based sources of information will be the greatest obstacles to ranchers' Internet use.

Hypothesis 5. There will be regional differences in the barriers to Internet use associated with accessibility (namely lack of access to the
Web, slow connections, and unreliable connections) due to differences in communication technology infrastructure.

\section{Methods}

We used a mixed-methods approach, combining a mail survey and qualitative interviews of ranchers in Colorado and Wyoming. The mail survey constitutes the backbone of the study, while the qualitative interviews were used to both inform the design of questions on the survey and interpret the quantitative results.

\section{Sampling Frame}

The National Agricultural Statistical Service in Denver compiled a list of potential participants who met the following criteria: own more than 20 animal units and manage at least 100 acres (40.47 ha) or more of private, public, or leased pastures. Feedlots and dairies were excluded because their land management practices and economic goals are different from ranchers'. Six regions of Colorado and Wyoming were targeted (Supplement A1, available online at https://doi.org/10.1016/j. rama.2018.12.009). A random sample of 200 ranchers was selected from each of the six regions, for a total of 1200 survey recipients. These procedures followed the same protocol and targeted the same regions as a previous survey conducted in 2009 (Kelley, 2010).

\section{Survey Instrument Design}

We developed questions for the survey on the basis of the need to evaluate two outreach projects, as well as obtain new data on range management practices and information-seeking behavior. A number of questions were retained from a previous survey sent in 2009 to the same sample of ranchers in order to facilitate analysis of changes over time.

Questions about Internet use were new in the 2013 survey and were developed on the basis of qualitative interviews with ranchers and natural resource professionals. The 2013 survey was not pretested because a similar instrument was tested and implemented in 2009. The survey contained sections regarding operation characteristics, natural resource management goals, management practices, perceptions of specific management practices, information needs and producer background. The section on information needs held the questions regarding Internet access and use.

\section{Survey Implementation}

The survey was implemented in four phases on the basis of a modification of Dillman's method (2000), including a presurvey letter, survey, reminder postcard, and replacement survey. After approximately 2 wk without receiving new responses, the National Agricultural Statistics Service (NASS) office in Cheyenne conducted a nonresponse bias check via telephone with $>10 \%$ of the nonrespondents.

\section{Measurement of Central Concepts}

Most questions were structured such that responses would be a dichotomous yes or no, including check boxes to indicate management practices or information sources used. Many questions were framed as scales, where variables were intended to measure degrees of influence on management decisions or degrees of agreement or disagreement with a statement. Half of the back cover was left blank with an invitation to write any additional comments following completion of the survey.

\section{Patterns of Internet Access}

Three questions asked specifically about methods of Internet access, frequency of access, and barriers to Internet access. Respondents were asked to check all methods of Internet access they use or mark the 
check box for no access if they have no Internet access. Frequency of Internet use was measured by means of an ascending 5-point scale ranging from nonuse of the Web to daily use.

To assess barriers to Internet use, one question listed nine potential obstacles to Internet use and asked rancher respondents to check all that apply and indicate which barrier was the single largest obstacle to greater use of the Internet on the ranch. The list of obstacles was compiled on the basis of qualitative interviews carried out before drafting the instrument. Finally, we asked ranchers to mark which information sources on a list they used the Web to access.

\section{Reliance on the Web for Decision Making}

Twenty-five variables measured ranchers' self-reported reliance on the Web to make decisions. One question asked generally about the importance of the Internet for day-to-day operation management, with a 5-point scale ranging from "not at all important" to "extremely important." A list of 24 ranch and rangeland management topics was provided, with respondents asked to indicate to what degree the Internet influences their decisions in each management area. These questions also used a 5-point scale, from "not at all" to "very high degree." Because this section was intended to determine how ranchers with Internet access integrate it into their management, we coded any responses from respondents with no access as missing. The questions were grouped into three management areas: ranch business management, resource management, and livestock herd management.

\section{Risk Tolerance}

The question about risk tolerance asked ranchers to choose which of five categories best matched their approach to the adoption of new innovations. The five categories were directly based on Rogers' (2003) five categories of adopters: innovators, early adopters, early majority, late majority, and laggards. The question provided brief descriptions of each approach from which ranchers selected the approach they felt best matched themselves. Responses were entered into the database on a scale of $1-5$, with 5 fitting Rogers' (2003) innovator category and 1 being late or nonadopters.

\section{Survey Analysis}

We carried out analysis of the data using the Statistical Package for the Social Sciences program, version 21 (IBM SPSS Statistics for Windows, 2012). Surveys were included if they were not blank, and one survey was excluded because it was a dairy operation. Data were checked for potential sampling bias by running chi-squared tests and analysis of variance to determine if the nonresponse check data differed from the mailed survey data. Respondents to the bias check had a slightly higher average gross annual income than respondents to the mailed survey ( 0.5 higher on a 9-point scale) and were an average of 5 yr younger. There were no statistical differences in other variables such as educational level, reliance on the Internet, or risk tolerance. On the basis of these results, we incorporated the bias check responses into our dataset.

To determine how many ranchers had more than one method of accessing the Internet, we computed an index of the number of access methods each rancher respondent used. This index was the sum of the number of devices respondents indicated they used.

We carried out a mediation analysis using the three-step approach put forth by Baron and Kenny (1986) to determine if risk tolerance acted as a mediating variable, as we hypothesized. We used Sobel's (1982) method to test the significance of mediation. After determining the degrees of mediation, we altered our model and conducted a multiple regression analysis with reliance on the Internet as a dependent variable and age, education, and risk tolerance as predictor variables.

We used chi-squared analyses to assess whether there are regional differences in the following obstacles to Internet use: lack of Internet access, slow Internet speed, and unreliable/intermittent Internet connection.
We used cluster analysis to detect and characterize different patterns of Internet use by ranchers. We ran a factor analysis of each of the three subsections of the 24 questions asking about the degree to which online information influences ranchers' decisions in the specific management areas: ranch business management, resource management, and livestock herd management. On the basis of the results of factor analyses of each of the three subsections of the variables and the conceptual coherence of variable groupings, we compiled four indices by averaging the responses in the selected variables. The ranch business management variables were split into two indices: the sales and purchases index and the business management index (Table 1). The other two subsections, resource management and livestock herd management, formed the remaining two indices based on the factor analyses, which grouped all the variables of each subsection together.

We ran K-means cluster analyses with SPSS adapted from the methodology of Vaske et al. (2004). We ran four cluster tests ranging from two to five clusters to facilitate comparison. We checked the results of each analysis against the tests with one more or one fewer cluster using crosstabs, to determine the best balance between nuanced and simple clusters. The cluster test with four clusters most ably differentiated ranchers' reliance on the Internet in various facets of operation management while maintaining the generalizability of our findings.

\section{Qualitative Interviews}

Qualitative data were gathered by means of semistructured interviews. We began the interviews before drafting the survey to facilitate question design and continued our interviews during and after the time period when surveys were sent and returned. Participants were recruited with a convenience and snowball approach, whereby ranchers or natural resource professionals we had already met were asked to participate and to recommend other individuals for potential recruitment.

We conducted six interviews with seven ranchers, interviewing one couple together due to their complementary use of the Internet and one couple separately because they had described their Internet use patterns as dissimilar. The other two participants were the only participants interviewed in their families.

We used an interview guide to ensure consistency in the questions we asked; however, to maintain the flow of conversation and the engagement of participants, the interviews were semistructured. Interviews were audio recorded, transcribed, and coded. This research was conducted under Colorado State University IRB Protocol 09-1190H.

\section{Interview Analysis}

Coding is the process in which actions and topics that are present in the data are assigned a word or phrase intended to be "essence capturing" (Saldana, 2012). First, we took notes on the topics and patterns we found in each of the interviews. Next, we reexamined our notes and applied a standardized set of codes on the basis of common topics and themes that came up in the interviews.

\section{Table 1}

Results of a factor analysis of 10 facets of ranch management using varimax with Kaiser normalization to compute new variables with which we conducted a cluster analysis.

\begin{tabular}{llll}
\hline Variables & Component 1 & Component 2 & Variable formed \\
\hline Livestock purchasing & .814 & - & Ranch sales and \\
Livestock marketing & .868 & - & purchases \\
Buying/selling equipment & .668 & - & \\
Buying/selling feed or hay & .625 & .465 & \\
Infrastructure development & .469 & .533 & Ranch business \\
Energy development & .603 & .406 & management \\
Tourism/hunting & - & .444 & \\
Participation in government & - & .720 & \\
$\quad$ programs & & .824 & \\
Conservation easements & - & .711 & \\
Estate planning & - & & \\
\hline
\end{tabular}


The most substantive analysis came from organizing the codes into matrices, domains, and taxonomies (Spradley, 1979; Gibbs, 2007). Domains are a way of grouping codes or concepts by virtue of their role or expression in a larger process, forcing the researcher to contextualize smaller units of data into larger concepts. We took these concepts and converted them into a taxonomy, which as the name implies is a hierarchical organization of themes, concepts, and then codes based on shared characteristics. Taxonomic themes included types of information sought online, reported benefits of Internet use, drawbacks of the Internet as a source of information, methods of Internet access, and preferred types of digital media.

After comparing these taxonomies of concepts to our research questions, we formulated matrices to compare and contrast responses. Matrices are essentially comparative tables, with a coding category on one side -such as obstacles to using the Internet to augment ranches-and the three interviews as comparative categories. These help visually establish commonalities among participants, as well as differences. Information sources, barriers to Internet use, and topics searched for on the Internet were incorporated from these matrices into survey questions as variables.

\section{Results}

The adjusted response rate for the survey was $34 \%$. To calculate the adjusted response rate, we subtracted the number of undeliverable surveys and the number of respondents who no longer fit our sampling parameters from the 1200 surveys sent and included the responses to our bias check in the total number of responses (259 valid mailed surveys and 136 bias check responses). Response rates were similar across regions ( $n=60-72$ ), with the exception of a lower response rate in southeast Wyoming $(n=53)$ (Tables 1 and 2$)$.

\section{Respondents' Characteristics}

Respondents had an average age of $60.5 \mathrm{yr}$ old (range 24-92), which was older than the national (58.3), Colorado (58.0), and Wyoming (58.2) average ages for primary operators on all farms (see Supplement A). Respondents had been managing their operations for 28.6 $\mathrm{yr}$, which is longer than national and state averages for all primary operators (Supplement A). The average rancher respondent received $46.4 \%$ of their gross annual income from livestock, relied on private property for $77.4 \%$ of their ranching land, sourced $86.1 \%$ of their labor from family members, and owned livestock holdings totaling 238 animal units. Most ranchers finished high school and completed $\geq 1 \mathrm{yr}$ of college, and $37.7 \%$ obtained a college or postgraduate degree (see Supplement A). The median gross annual income for respondents was between 80000 and 199000 dollars (see Supplement A).

\section{Table 2}

Percentage of rancher respondents who reported using the Internet to access the listed sources. The total number of respondents to each question is listed in the column on the right due to the low response rate to this question.

\begin{tabular}{lcl}
\hline Source & $\begin{array}{l}\text { Percent who have accessed } \\
\text { this source online } \\
\text { (no. who have used the source) }\end{array}$ & $\begin{array}{l}\text { Total no. of } \\
\text { respondents }\end{array}$ \\
\hline Extension & $39.7(29)$ & 73 \\
Private companies & $39.2(20)$ & 51 \\
Industry magazines & $36.2(25)$ & 69 \\
Scientific journals & $35.8(19)$ & 53 \\
Environmental organizations & $1.9(1)$ & 54 \\
County or city weed authority & $9.2(6)$ & 65 \\
Local or regional newspaper & $23(14)$ & 61 \\
State government agency & $18.8(12)$ & 64 \\
Federal agency & $37(27)$ & 64 \\
Conferences or workshops & $26.6(17)$ & 74 \\
Family, friends, peers & $13.5(10)$ & 66 \\
Agricultural organizations & $28.8(19)$ & 52 \\
Professional associations & $19.2(10)$ &
\end{tabular}

\section{Method and Frequency of Internet Access}

Most respondents (76.1\%) reported having Internet access, with $63.7 \%$ having high-speed access, $14.3 \%$ using smartphones with Internet access, and $9.8 \%$ using dial-up connections. Nearly $24 \%$ reported that they have no access to the Internet from their ranches. Of ranchers with Internet access, $84.7 \%$ used only one device to access the Web, while $15.3 \%$ reported having two methods of accessing the Web. A slight majority of ranchers, $51.1 \%$, reported accessing the Internet on a daily basis, while $10.7 \%$ reported using it rarely and $20.2 \%$ indicated they never accessed the Internet.

\section{Ranchers' Rangeland and Ranch Management Information Seeking}

Almost $40 \%$ of ranchers reported using the Internet to access information from Extension, private ranching and range-related companies, industry magazines, scientific journals, and federal agencies (see Table 1). Between $20 \%$ and $30 \%$ of respondents used the Web to access local or regional newspapers, conferences or workshops, and agricultural organizations (see Table 2).

Respondents were given a list of potential uses of the Internet and asked to indicate which topics they used the Internet to find information about. Respondents (including respondents with no internet access) reported that they had used the Internet to look up grazing management (42.2\%), drought management (38.3\%), rangeland monitoring (26.6\%), cheatgrass management $(12.5 \%)$, and state-andtransition models (5.5\%). Approximately $51 \%$ of all respondents (including those without Internet access) indicated they had never used the Internet to look up any of those five topics (see Table 2).

\section{Influence of the Internet on Rancher Decision Making}

The degree of influence information ranchers found online had on their decisions varied by topic. Online weather forecasts had a moderate to high degree of influence on management decisions for $84.2 \%$ of respondents with Internet access-the most influence of any type of online information listed in the survey (Tables 3-5).

Online information also influenced ranchers' economic decisions. A majority of respondents indicated that information they obtained on the Web had a moderate to high degree of influence on livestock marketing (62.2\%), buying or selling ranch equipment (61.1\%), and livestock purchases (53.2\%). Almost half of respondents indicated a similar degree of influence for purchasing hay or feed (48.7\%), while $42.8 \%$ reported a moderate to high degree of influence on their decisions regarding infrastructure development (see Table 3).

Online information had less influence on ranchers' natural resource management decisions compared with their ranch business decisions. About half of respondents indicated online information had a moderate to high influence on their decisions regarding drought mitigation and management. More than $40 \%$ of respondents reported a moderate to high influence of online information to their decisions about managing invasive or weedy species (40.6\%) and grazing management (43.1\%).

The majority of ranchers with Internet access reported the Internet had moderate to high degrees of influence on their livestock management decisions, with the exception of information relating to lowstress handling (43.1\%). More than half of respondents reported that Web-based information influenced livestock genetics (60.4\%), health (63.2\%), and nutrition (57\%) to a moderate or higher degree.

\section{Factors Associated with Increased Internet Use}

We hypothesized that wealth, operational scale (in acres of private land and animal units), risk tolerance, education, and age would be the best predictors of Internet use in the day-to-day management of their ranches. The regressions we conducted demonstrated that risk tolerance partially or fully mediated the relationship between each of the 
Table 3

Ranchers were asked to what extent the Internet influences decisions in each of the categories below on a 5-point scale, with 1 being not at all, and 5 being a very high degree.

\begin{tabular}{|c|c|c|c|c|c|c|c|c|}
\hline \multirow[t]{2}{*}{ Category (no. of valid responses) } & \multirow[t]{2}{*}{ Mean } & \multirow[t]{2}{*}{ Median } & \multirow[t]{2}{*}{ Standard error } & \multicolumn{5}{|c|}{ Percent of respondents } \\
\hline & & & & Not at all & Slight degree & Moderate degree & High degree & Very high degree \\
\hline \multicolumn{9}{|l|}{ Ranch business management } \\
\hline Livestock purchasing (158) & 2.51 & 3 & .095 & 27.2 & 19.6 & 35.4 & 10.8 & 7 \\
\hline Livestock marketing (164) & 2.84 & 3 & .097 & 18.3 & 19.5 & 32.9 & 18.3 & 11 \\
\hline Buying/selling equipment (162) & 2.83 & 3 & .092 & 14.8 & 24.1 & 35.2 & 15.4 & 10.5 \\
\hline Buying/selling feed or hay (158) & 2.47 & 2 & .095 & 27.2 & 24.1 & 29.1 & 13.9 & 5.7 \\
\hline Infrastructure development (157) & 2.33 & 2 & .089 & 28.0 & 29.3 & 28.7 & 9.6 & 4.5 \\
\hline Energy development (136) & 1.96 & 2 & .091 & 44.1 & 25.7 & 23.5 & 2.9 & 3.7 \\
\hline Tourism/hunting (133) & 1.67 & 1 & .088 & 60.9 & 21.8 & 8.3 & 7.5 & 1.5 \\
\hline Participation in government programs (147) & 2.0 & 2 & .085 & 40.1 & 29.9 & 21.8 & 6.1 & 2.0 \\
\hline Conservation easements (141) & 1.53 & 1 & .068 & 62.4 & 25.5 & 9.2 & 2.1 & 0.7 \\
\hline Estate planning (146) & 1.95 & 2 & .093 & 47.3 & 24.7 & 19.2 & 4.1 & 4.8 \\
\hline \multicolumn{9}{|l|}{ Resource management } \\
\hline Weather forecast/prediction (171) & 3.69 & 4 & .096 & 8.2 & 7.6 & 26.9 & 21.6 & 35.7 \\
\hline Rangeland assessment or monitoring (158) & 2.03 & 2 & .079 & 36.7 & 32.3 & 24.1 & 5.1 & 1.9 \\
\hline Invasive species or weed management (160) & 2.24 & 2 & .083 & 30.0 & 29.4 & 30.0 & 8.1 & 2.5 \\
\hline Grazing management (160) & 2.31 & 2 & .090 & 30.6 & 26.3 & 30.0 & 8.1 & 5 \\
\hline Rangeland seeding (150) & 1.96 & 2 & .083 & 42.0 & 28.7 & 23.3 & 3.3 & 2.7 \\
\hline Prescribed fire (145) & 1.46 & 1 & .063 & 67.6 & 22.1 & 8.3 & 1.4 & 0.7 \\
\hline Wildlife or habitat management (154) & 1.92 & 2 & .078 & 42.2 & 31.2 & 21.4 & 3.2 & 1.9 \\
\hline Drought management (160) & 2.42 & 2.5 & .091 & 29.4 & 20.6 & 31.3 & 16.3 & 2.5 \\
\hline $\begin{array}{l}\text { Wildfire or other natural disaster } \\
\text { preparedness/recovery (152) }\end{array}$ & 2.03 & 2 & .089 & 40.8 & 28.9 & 19.7 & 7.2 & 3.3 \\
\hline Predator control (154) & 1.97 & 2 & .095 & 48.7 & 22.1 & 18.2 & 5.8 & 5.2 \\
\hline \multicolumn{9}{|l|}{ Livestock herd management } \\
\hline Livestock genetics/breeding (164) & 2.8 & 3 & .099 & 20.1 & 19.5 & 32.3 & 16.5 & 11.6 \\
\hline Livestock health/veterinary care (166) & 2.81 & 3 & .094 & 19.3 & 17.5 & 34.9 & 19.3 & 9 \\
\hline Feeding/nutrition/forage quality (163) & 2.58 & 3 & .091 & 24.5 & 18.4 & 37.4 & 14.1 & 5.5 \\
\hline Low stress livestock handling (160) & 2.34 & 2 & .096 & 31.3 & 25.6 & 28.1 & 7.5 & 7.5 \\
\hline
\end{tabular}

demographic variables and reliance on the Internet except for the number of animal units owned (animal units showed no relationship to the mediator or criterion variables). Risk tolerance fully mediated both gross annual income and private acres owned, while partially mediating age and the last year of formal education completed. Sobel's test of the significance of mediation (see Table 4) demonstrated that all the variables shown to be mediated by the regression tests were significantly mediated (Figs. 1-5). These tests confirmed our hypothesis that risk tolerance mediated the relationship between rancher demographic characteristics and their use of the Internet for ranch management, with the exception of animal units owned.

Gross annual income and private acres owned were excluded from the final regression model because they were fully mediated. The final model regressed age, last year of school completed, and risk tolerance as predictor variables on reliance on the Internet for daily ranch management as the dependent variable (see Table 5). This model accounted for $18 \%$ of the variation and had a typical to substantial effect size (.436) (Vaske, 2008). Thus, younger ranchers, ranchers with more formal education, and ranchers with greater risk tolerance are all more likely to report a heavier reliance on the Internet for ranch management decisions. Ranchers with higher gross income and more private acres were more tolerant of taking risks and, therefore, were indirectly more likely to use the Internet due to the full mediating effect of risk tolerance on Internet reliance.

\section{Table 4}

We used Sobel tests (1982) to determine if mediation was significant or not with risk tolerance as the mediator and reliance on the Internet as the criterion variable.

\begin{tabular}{llll}
\hline Predictor variables & $z$ value & Standard error & $P$ value \\
\hline Education & 2.895 & .022 & $.004^{1}$ \\
Gross annual income & 2.825 & .021 & $.004^{1}$ \\
Age & 2.763 & .002 & $.005^{1}$ \\
Private acres & 2.404 & .015 & $.02^{2}$ \\
\hline
\end{tabular}

1 Significant at the $P<.01$ level.

2 Significant at the $P<.05$ level.

\section{Barriers to Internet Use}

On the basis of information foraging theory (Pirolli and Card, 1999), we hypothesized that lack of time to find information online and lack of trust in Web-based sources of information would be the greatest obstacles to ranchers' Internet use. Lack of time was the most frequent response, with $21.5 \%$ of respondents listing time as the single biggest barrier to greater Internet use. No Internet access (13\%), lack of experience using the Web to find information (12.4\%), and difficulty determining which online sources to trust (11.9\%) were the next most cited obstacles to increased reliance on the Web. These results confirm our hypothesis that lack of time would be the most significant barrier. We reject our hypothesis that determining which websites to trust would be the second most important barrier, as it was the biggest barrier for approximately 1 in 10 respondents but not the second most common primary barrier (Supplement B, available online at https://doi.org/10. 1016/j.rama.2018.12.009). However, lack of trust was the second most commonly reported of all barriers when ranchers were asked to check all the barriers that applied rather than the single biggest barrier (see Supplement B). Approximately 1 in 3 ranchers indicated it was a barrier, but only about 1 in 10 indicated it was the biggest barrier.

Data from qualitative interviews indicated that local connectivity issues may pose some barriers to increased adoption of the Internet on

Table 5

This regression model excluded all variables fully mediated by risk orientation to provide a predictive model for reliance on the Internet by ranchers with known age, education, and risk tolerance characteristics.

\begin{tabular}{llllll}
\hline Variable & Adjusted $r^{2}$ & $\begin{array}{l}\text { Standard error } \\
\text { of the estimate }\end{array}$ & Standardized $\beta$ & $\mathrm{t}$ & $P$ value \\
\hline Age & .183 & 1.167 & -.248 & -4.763 & $<.001^{1}$ \\
Education & & & .187 & 3.575 & $<.001^{1}$ \\
Risk & & .223 & 4.206 & $<.001^{1}$ \\
$\quad$ Orientation & & & & \\
\hline 1 Significant at the $P<.01$ level.
\end{tabular}




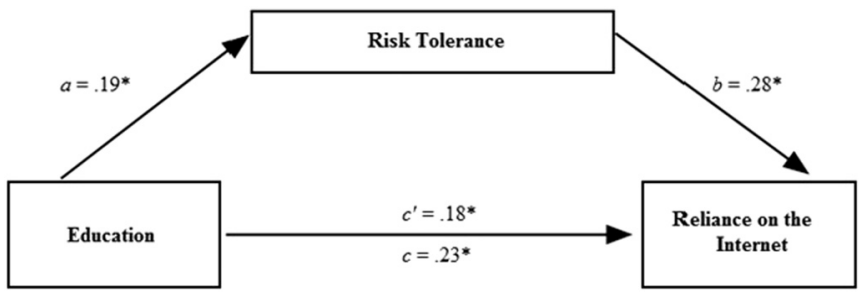

Figure 1. Test of mediation with reliance on the internet as a criterion variable, risk tolerance as the mediator, and education as the predictor variable. Partial mediation was confirmed. *All standardized coefficients were significant at the $\mathrm{p}<.05$ level. $\mathrm{a}=$ Coefficient value of the mediator variable regressed on the predictor variable (Adjusted $\left.\mathrm{R}^{2}=.03\right) \mathrm{b}=$ Coefficient value of the criterion variable regressed on the mediator variable (Adjusted $\left.\mathrm{R}^{2}=.12\right) \mathrm{c}=$ Coefficient value of the criterion variable regressed on the predictor variable (Adjusted $\mathrm{R}^{2}=.05$ ) $\mathrm{C}^{\prime}=$ Coefficient value of the criterion variable regressed on the predictor variable, when the mediator variable is included in the regression (Adjusted $\mathrm{R}^{2}=.12$ )

ranches in rural areas. We hypothesized that regional differences in infrastructure development necessary for reliable Internet access would result in significant differences in the reported barriers to Web use. Chi-squared tests comparing geographic regions of respondents to three variables measuring connectivity issues found a significant difference in perceptions of Internet speed across regions $(P=.034)$ and no significant differences across regions in terms of lack of Internet access or intermittent/unreliable connections. Ranchers in northwest Colorado and southeast Wyoming reported slow connections as a barrier to Internet use more frequently than did other regions (see Supplement B).

\section{Typology of Web-Using Ranchers}

A cluster analysis identified four distinct groups of ranchers on the basis of their responses to questions asking about the degree of influence online information has on specific range and ranch-related topics (Table 6 ). The first cluster (26.8\% of respondents with Internet access) was "not at all" influenced by online information in their ranch management decisions.

The second cluster ( $40.1 \%$ of respondents with Internet access) reported a "moderate degree" of influence of online information on decisions involving ranch purchases or sales (e.g., equipment purchases or livestock marketing) and livestock herd management. This group reported only a "slight" influence of online information on natural resource management and business management decisions (see Table 6).

The third group was characterized by a "moderate degree" of influence in all four indices of ranch management topics (25.4\% of respondents with Web access). The mean in all four ranch management indices for this group ranged between 2.6 and 3.2 on the scale,

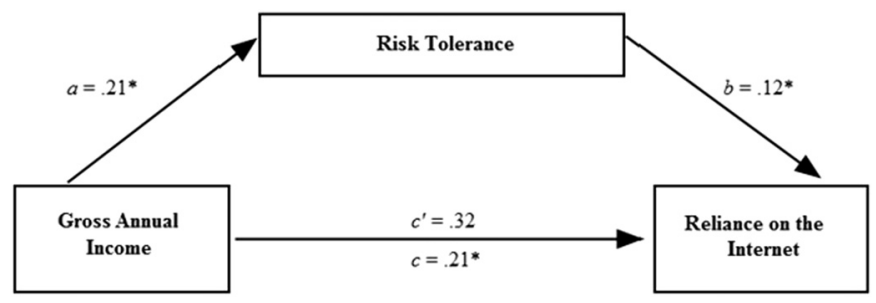

Figure 2. Test of mediation with reliance on the internet as a criterion variable, risk tolerance as the mediator, and income as the predictor variable. Full mediation was confirmed. *All standardized coefficients were significant at the $\mathrm{p}<.05$ level. $\mathrm{a}=$ Coefficient value of the mediator variable regressed on the predictor variable (Adjusted $\left.\mathrm{R}^{2}=.04\right) \mathrm{b}=$ Coefficient value of the criterion variable regressed on the mediator variable (Adjusted $\left.\mathrm{R}^{2}=.12\right) \mathrm{c}=$ Coefficient value of the criterion variable regressed on the predictor variable (Adjusted $\mathrm{R}^{2}=.04$ ) $\mathrm{c}^{\prime}=$ Coefficient value of the criterion variable regressed on the predictor variable, when the mediator variable is included in the regression (Adjusted $\mathrm{R}^{2}=.12$ )

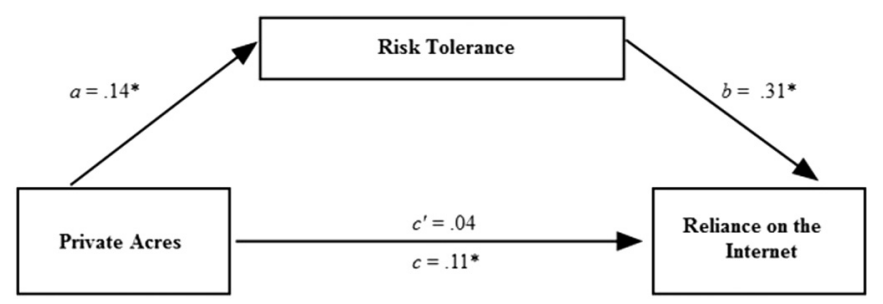

Figure 3. Test of mediation with reliance on the internet as a criterion variable, risk tolerance as the mediator, and private acres as the predictor variable. Full mediation was confirmed. *All standardized coefficients were significant at the $\mathrm{p}<.05$ level. $\mathrm{a}=$ Coefficient value of the mediator variable regressed on the predictor variable (Adjusted $\left.\mathrm{R}^{2}=.02\right) \mathrm{b}=$ Coefficient value of the criterion variable regressed on the mediator variable (Adjusted $\mathrm{R}^{2}=.01$ ) $\mathrm{c}=$ Coefficient value of the criterion variable regressed on the predictor variable (Adjusted $\mathrm{R}^{2}=.01$ ) $\mathrm{c}^{\prime}=$ Coefficient value of the criterion variable regressed on the predictor variable, when the mediator variable is included in the regression (Adjusted $\mathrm{R}^{2}=.01$ )

indicating a consistently moderate influence of the Internet on ranch management decisions for ranchers in this cluster.

The fourth group was the smallest (7.7\% of respondents) but emerged as a distinct cluster in every test run with more than two clusters. This group indicated online information had a "high degree" of influence on their ranch purchases and sales, as well as livestock herd management decisions. They also reported a "moderate degree" of influence of Web-based information on their business management and resource management decisions. This group could best be characterized as Web oriented.

We combined groups 3 and 4 due to 4's low sample size and determined that $33.1 \%$ of ranchers with Internet access report a moderate to high degree of influence on any of the four ranch management areas. In the ranch sales and purchases and livestock herd management areas, $73.2 \%$ of ranchers with Internet access fell into clusters characterized by moderate to high degrees of influence by Webbased information.

\section{Who Are the Digital Ranchers?}

Our cluster analysis demonstrated that ranchers can be loosely grouped into four patterns of Internet use. Here we supplement these results with the results of our qualitative data analysis to better understand how ranchers in each category described using the Web.

\section{No Influence}

The results of the cluster analysis indicate that approximately one in four ranchers with Internet access make little or no use of it for ranch decision making. The possible reasons for this are manifold-some ranchers may lack the time to access it frequently enough, others may

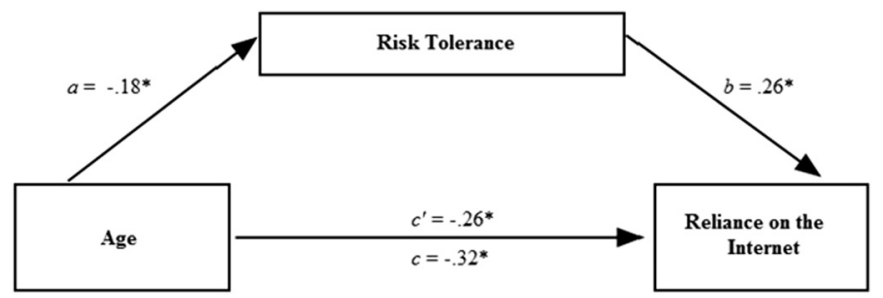

Figure 4. Test of mediation with reliance on the internet as a criterion variable, risk tolerance as the mediator, and age as the predictor variable. Partial mediation was confirmed. *All standardized coefficients were significant at the $\mathrm{p}<.05$ level. $\mathrm{a}=$ Coefficient value of the mediator variable regressed on the predictor variable (Adjusted $\left.\mathrm{R}^{2}=.03\right) \mathrm{b}=$ Coefficient value of the criterion variable regressed on the mediator variable (Adjusted $\left.\mathrm{R}^{2}=.15\right) \mathrm{c}=$ Coefficient value of the criterion variable regressed on the predictor variable (Adjusted $\mathrm{R}^{2}=.10$ ) $\mathrm{c}^{\prime}=$ Coefficient value of the criterion variable regressed on the predictor variable, when the mediator variable is included in the regression (Adjusted $\mathrm{R}^{2}=.15$ ) 


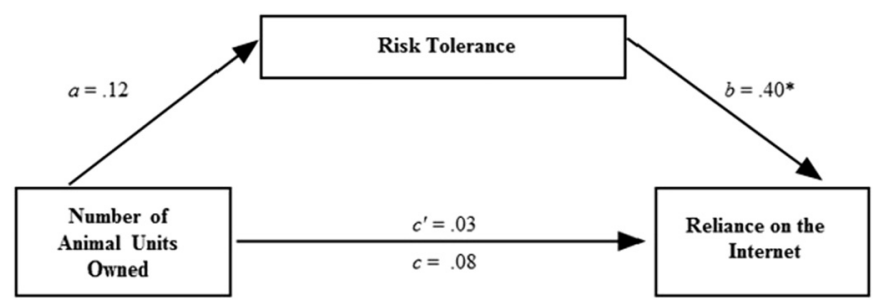

Figure 5. Test of mediation with reliance on the internet as a criterion variable, risk tolerance as the mediator, and the number of animal units as the predictor variable. No mediation was confirmed. *All standardized coefficients were significant at the $p<.05$ level. $\mathrm{a}=$ Coefficient value of the mediator variable regressed on the predictor variable (Adjusted $\left.\mathrm{R}^{2}=.01\right) \mathrm{b}=$ Coefficient value of the criterion variable regressed on the mediator variable (Adjusted $\mathrm{R}^{2}=.15$ ) $\mathrm{c}=$ Coefficient value of the criterion variable regressed on the predictor variable (Adjusted $\mathrm{R}^{2}=.00$ ) $\mathrm{c}^{\prime}=$ Coefficient value of the criterion variable regressed on the predictor variable, when the mediator variable is included in the regression (Adjusted $\mathrm{R}^{2}=.15$ )

see no need for it because their informational needs are met elsewhere, and some ranchers may have Internet access but lack the familiarity with Web use to incorporate it fully. As one rancher described, ranchers with entrenched information-seeking habits may find it difficult or see it as unnecessary to integrate a new source of information into their operation:

"But just, I guess, by a lifetime of habit, I'm more used to referring, you know, my questions, referring to neighbors who may know something about what I'm looking for. The CSU Extension office, I use them a lot, a tremendous amount. Also our NRCS, you know, Natural Resource Conservation Service, I rely on them quite a bit too for help. And the FSA [Farm Service Agency]."

\section{Sales and Herds}

Other ranchers rely on the Internet to a moderate degree when it comes to decisions about sales and purchases of livestock and ranch equipment, as well as making decisions affecting livestock genetics, health, nutrition, and handling.

Two of our six interviewees described Internet use patterns closely matching this statistical cluster. Both of these ranchers rely primarily on the Internet for information on livestock markets and animal health.

"I would say that the primary use for our Internet-for the Internet-has been checking on market conditions, but also we use it for business communications, vet books-we look up the Merck veterinary manual online frequently[. . ]And we've used the Internet to price equipment, to find out where to buy it and what to buy both with the chemicals and with the spraying equipment. It was useful for that."

"I do a lot of market searches checking livestock markets and futures markets. I do a lot of communication with, on behalf of the, with the state livestock board of immunizations [...]"
Although one of these ranchers has a spouse who used the Internet to look up other topics, both of the participants quoted earlier emphasized during the interviews that purchases and sales and topics related to livestock herd management formed the bulk of their personal online activity.

Moderate Web Users

This group of digitally savvy ranchers is characterized by a moderate reliance on Web-based information for all the categories of ranch management we measured. The moderate degree of influence reported by respondents in this category indicates their use of the Web to find information on a wide range of topics rather than a specific subset of management issues. One interviewee who best matches this category reported looking up such diverse topics as snowpack levels, weed spraying practices, plant identification, wildfire locations and severity, henhouse plans, and bull prices online. Nevertheless, she indicated the Internet remained but one of many information sources for her if she had a question about a specific topic:

"First I would ask a person. Maybe a couple of people. And then I might look it up on the Internet. And talk to the Extension agent."

\section{Web-Oriented Ranchers}

The smallest cluster delineated in the analysis consists of ranchers whose decisions in ranch sales and purchases and livestock herd management are highly influenced by the Web. Their decisions in resource management and business management were moderately influenced by online information.

Of the interviewees, the couple with similar Internet habits most closely matches this category. Though one of the pair had grown up on a ranch, both had made significant incomes in off-ranch careers and had been highly educated in their fields before purchasing their property at an age far younger than our average survey respondents or other interviewees. They had a ranch website and conducted much of their ranching business online. The couple reported looking up similar topics as our "moderate Web user" interviewee but placed much higher emphasis on the importance of the Web for their ranch management: "I think the Internet will continue to be an increasingly valuable tool," one stated. This aligns with our survey findings regarding age, education, and risk tolerance predicting Internet dependence.

\section{Discussion}

\section{Internet Use is Widespread}

The results of our survey indicate that most ranchers in the six regions surveyed had integrated the Internet into their operations to some extent, and many used it regularly to inform their management. As one rancher interviewee stated, "Everybody's on the Internet some"while this is not true in a literal sense, our results show that even

\section{Table 6}

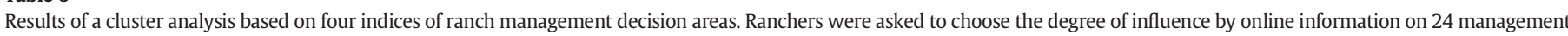
areas on a scale of $1-5$, with 1 being "not at all" and 5 being a "very high degree" of influence. Percentages reported are from respondents with Internet access on the ranch.

\begin{tabular}{|c|c|c|c|c|c|}
\hline \multirow[t]{2}{*}{ Cluster group } & \multicolumn{4}{|l|}{ Mean } & \multirow{2}{*}{$\begin{array}{l}\text { Percent of respondents } \\
(n=142)\end{array}$} \\
\hline & Ranch sales \& purchases & Business management & Resource management & Livestock herd management & \\
\hline $\begin{array}{l}\text { No influence } \\
\text { (Group 1) }\end{array}$ & 1.5 & 1.2 & 1.3 & 1.4 & 26.8 \\
\hline $\begin{array}{l}\text { Sales and herds } \\
\text { (Group 2) }\end{array}$ & 2.6 & 1.7 & 2.2 & 2.8 & 40.1 \\
\hline $\begin{array}{l}\text { Moderate Web users } \\
\text { (Group 3) }\end{array}$ & 3.1 & 2.6 & 2.9 & 3.2 & 25.4 \\
\hline $\begin{array}{l}\text { Web oriented } \\
\text { (Group 4) }\end{array}$ & 4.4 & 2.8 & 3.0 & 4.4 & 7.7 \\
\hline
\end{tabular}


some ranchers with no Internet access on the ranch have gone online. About $17 \%$ of the respondents with no Internet access on their ranches reported infrequently accessing the Internet elsewhere, indicating that even ranchers with no access to the Web at home may seek off-ranch access-the rancher's statements in the interview aptly summarize our results.

The cluster of moderate Web users aligns with prior research from Iowa, which found that producers use the Web to keep careful track of the market conditions influencing their income and expenses (Arbuckle et al., 2011). However, the same study from Iowa reported a low use of the Internet to look up information on livestock production, which suggests possible regional differences in Internet use with regards to livestock herd management.

A prior survey asking respondents about Internet use in Wyoming reported that $82 \%$ of respondents had Internet access and $42 \%$ of respondents with Internet access used the Internet daily (Kachergis et al., 2013). Although our survey had a slightly lower percentage of respondents with on-ranch access (76.1\%), we also found a higher percentage of ranchers who used the Internet on a daily basis $(51.1 \%$ of all respondents).

\section{Rancher and Ranch Characteristics Predict Internet Use}

Past research has demonstrated measurable links between the characteristics of a farm or ranch manager or their operation and the degree to which the Internet is integrated into their operation (Mishra and Park, 2005). Similarly, other studies have found links between these variables and the risk tolerance of a rancher (Kelley, 2010), as well as the adoption of new management practices (Kennedy and Brunson, 2007). Our results demonstrated similar relationships between a rancher's personal and operational characteristics and the degree to which they rely on the Internet. Age, education, and risk tolerance were significant predictors of dependence on the Internet for daily ranch management-younger ranchers, more educated ranchers, and ranchers who are more open to implementing new practices are all more likely to use the Internet. However, our model accounted for < $20 \%$ of the variance. Determining additional factors leading to greater Internet use will require additional investigation. In interviews, ranchers also commented on the existence of a generational gap in reliance on the Internet for finding information: "I think it's probably a generational thing, you know, the Internet came into my life pretty late and I'm just not used to using it. And I'm not as attuned to using it." Increasing rates of Internet use in rural areas and the changing demographics of today's ranchers may minimize the role of obstacles to Web use in the future.

\section{Internet as a Rangeland Science Outreach Tool}

The results of this study demonstrate that the Internet has great potential as an outreach tool, considering the degree of influence online information has on many ranchers and the approximately $40 \%$ of ranchers who indicated using the Web to access Extension and scientific journals. Like any tool, the Internet also has limitations. Our findings demonstrate that online information has a noteworthy impact on ranchers' decisions; however, our results do not provide evidence that the Internet was supplanting traditional print sources of information at the time of the survey.

At the scale of individual ranchers, our results confirmed that lack of time was the single largest barrier to greater dependence on the Web. The results also demonstrated that obstacles to ease of use (namely lack of experience using the Internet), finding information specific to a rancher's situation, and determining which sources to trust were commonly reported issues, with about one in three ranchers indicating them as obstacles (Supplement B). This corroborates the theoretical underpinnings of both Pirolli's and Card's information foraging theories (1999), which indicate that the ease with which information can be accessed acts as a constraint on the usefulness of a website for outreach purposes, as does the difficulty determining which digital information sources can be trusted.

Given the high level of weather variability in the regions of Colorado and Wyoming studied, online weather forecasts are important decisionsupport tools for ranchers year-round. Weather forecasts had a moderate to high degree of influence on management decisions for $84.2 \%$ of respondents to this study (see Table 3), but the specific application of this information to tactical, strategic, and operational ranch decision making over different time scales merits more research. Kachergis et al. (2014) surveyed Wyoming ranchers and found that only $16 \%$ of ranchers used weather forecasts to adjust stocking rates in preparation for drought (Kachergis et al., 2014). The high level of influence respondents reported for the Internet on livestock, hay, and equipment trade decisions suggests that the web provides valuable agribusiness networking opportunities that may increase flexibility for producers facing variable markets; however, ranching differs from other agricultural systems and market conditions across local and regional scales.

On a larger scale, our results provide potential target audiences for outreach professionals depending on the outreach project's goals. For example, digital outreach projects directly related to livestock herd management decisions could potentially exert a moderate to high influence on about $73 \%$ of ranchers with Internet access, whereas Web-based outreach regarding natural resource management could ostensibly exert a moderate to high influence on about $33 \%$ of respondents.

\section{Implications}

The demographics of ranchers in the West are changing. Brunson and Huntsinger (2008) point out that the ranching population of the West, like many rural populations, is aging-concordantly, the average respondent in our survey was $>60 \mathrm{yr}$ old. On the basis of these demographic trends and the significant inverse relationship we found between age and Internet reliance, it is likely that dependence on the Internet for finding information and making operational decisions will increase as properties are handed over to new managers in the coming years. Future research should seek to understand how ranchers engage with user-driven content, social media, and other mobile applications, as well as how that use changes over time. Additional research should evaluate the effectiveness of increased and evolving efforts by researchers and Extension professionals to make outreach materials available and consider nonrancher populations of rangeland stakeholders, including public agency employees.

The Internet's role in shaping range management decisions, ranching communities, and knowledge exchange among researchers and managers deserves further attention by agency professionals, consultants, and researchers seeking to exchange information with decision makers that improves adaptability and decision-making capacity. Specifically, the need for accessible information that increases flexibility and capacity to adapt to dynamic ecological, livestock management, and economic conditions is vital. These include marketing and trade information and weather forecasts that provide rancher-relevant, timely information for key decisions throughout the year. Because livestock health and genetics and ranch business management innovations are also pronounced areas of Internet information use relative to other types of management decision-making information, they are key opportunities for online knowledge exchange. We recommend that outreach websites minimize rancher constraints to Internet use by ensuring visitors can find relevant information quickly and take steps to ensure the website's credibility is readily perceptible. As risk tolerance was shown to significantly predict Internet reliance in our study, as well as the adoption of ranching innovations in previous studies (Kennedy and Brunson, 2007; Kelley, 2010), it is likely that online outreach could facilitate the diffusion of new rangeland management innovations across the majority of the ranching population in this region. 


\section{Acknowledgments}

We would like to thank rancher participants for their contribution to this work, as well as Jerry Vaske, Paul Meiman, and two anonymous reviewers for comments that improved earlier versions of the paper.

\section{Appendix A. Supplementary data}

Supplementary data to this article can be found online at https://doi. org/10.1016/j.rama.2018.12.009.

\section{References}

Arbuckle, J.G., Lasley, P., Ferrell, J., 2011. Iowa Farm and Rural Life Poll: 2011 Summary Report (No. 17). Extension Community and Economic Development Publicationslowa State University.

Baron, R.M., Kenny, D.A., 1986. The moderator-mediator variable distinction in social psychological research: conceptual, strategic, and statistical considerations. Journal of Personality and Social Psychology 51 (6), 1173.

Brunson, M.W., Huntsinger, L., 2008. Ranching as a conservation strategy: can old ranchers save the new West? Rangeland Ecology \& Management 61 (2), 137-147.

Didier, E.A., Brunson, M.W., 2004. Adoption of range management innovations by Utah ranchers. Rangeland Ecology \& Management 57 (4), 330-336.

Dillman, D.A., 2000. Mail and Internet surveys: the tailored design method (Vol. 2). Wiley, New York, NY, USA $464 \mathrm{p}$

DiMaggio, P., Hargittai, E., 2001. From the "digital divide"to "digital inequality": studying Internet use as penetration increases. Working Paper Series number 15. Princeton University Center for Arts and Cultural Policy Studies, Princeton, NJ, USA.

Gibbs, G.R., 2007. Analyzing Qualitative Data. 1 edition. SAGE Publications Ltd, London 176 p.

Grigsby, T.L., 1980. Today's riders of the purple sage: symbols, values, and the cowboy myth. Rangelands 2 (3), 93-96.

High, J., Jacobson, M., 2005. Internet-based natural resource extension. Journal of Extension 43 (3).

Hodge, H., Carson, Doris, Carson, Dean, Newman, L., Garrett, J., 2017. Using Internet technologies in rural communities to access services: the views of older people and service providers. Journal of Rural Studies 54, 469-478 Available at:. https://doi.org/ 10.1016/j.jrurstud.2016.06.016, Accessed date: 28 March 2018.

Hutchinson, B., Pfander, J., Tanaka, J., Clark, J., 2011. Rangelands West/Global Rangelands, eXtension Rangelands, and the Range Science Information System: a suite of new Web resources. Rangelands 33 (4), 55-63.

Hutchinson, B.S., Ruyle, G.B., 2006. Wired without the barbs: using the Internet for rangeland information. Rangelands 22 (6), 19-22.

IBM SPSS Statistics for Windows (version 21). IBM Corp., Armonk, NY, USA.

Kachergis, E., Derner, J., Roche, L., Tate, K., Lubell, M., Mealor, R., Magagna, J., 2013. Characterizing Wyoming ranching operations: natural resource goals, management practices and information sources. Natural Resources 4, 45-54.

Kachergis, E., Derner, J.D., Cutts, B.B., Roche, L.M., Eviner, V.T., Lubell, M.N., Tate, K.W., 2014. Increasing flexibility in rangeland management during drought. Ecosphere 5, 1-14.
Kelley, W.K., 2010. Rangeland managers' adoption of innovations, awareness of state and transition models, and management of Bromus tectorum. [master's thesis]. Colorado State University, Fort Collins, CO, USA.

Kennedy, C.A., 2005. Learning and application of range management innovations among ranchers in west-central Colorado. [master's thesis]. Utah State University, Logan, UT, USA

Kennedy, C.A., Brunson, M.W., 2007. Creating a culture of innovation in ranching. Rangelands 29 (3), 35-40.

King, D.A., Boehlje, M.D., 2000. Extension: on the brink of extinction or distinction. Journal of Extension 38 (5), 5COM1.

Lubell, M.N., Cutts, B.B., Roche, L.M., Hamilton, M., Derner, J.D., Kachergis, E., Tate, K.W., 2013. Conservation program participation and adaptive rangeland decision-making. Rangeland Ecology \& Management 66 (6), 609-620.

McGrath, C., Zell, D., 2001. The future of innovation diffusion research and its implications for management. Journal of Management Inquiry 10 (4), 386-391.

Metzger, M.J., Flanagin, A.J., Medders, R.B., 2010. Social and heuristic approaches to credibility evaluation online. Journal of Communication 60 (3), 413-439.

Mishra, A.K., Park, T.A., 2005. An empirical analysis of Internet use by US farmers. Agricultural and Resource Economics Review 34, 253-264.

National Agricultural Statistics Service (USDA NASS), 2012. Census of Agriculture, 2012 Census Full Report. https://www.nass.usda.gov/Publications/AgCensus/2012/\#full report, Accessed date: 13 September 2018.

Peterson, R., Coppock, D.L., 2001. Economics and demographics constrain investment in Utah private grazing lands. Journal of Range Management 54, 106-114.

Pirolli, P., 2005. Rational analyses of information foraging on the Web. Cognitive Science 29 (3), 343-373.

Pirolli, P., Card, S., 1999. Information foraging. Psychological Review 106 (4), 643-675.

Rogers, E.M., 2001. The digital divide. Convergence: The International Journal of Research into New Media Technologies 7 (4), 96-111.

Rogers, E.M., 2003. Diffusion of innovations. 5th ed. Simon and Schuster.

Rowan, R., White, L.D., 1994. Regional differences among Texas rangeland operators. Journal of Range Management 47, 338-343.

Saldana, J., 2012. The coding manual for qualitative researchers. 2nd ed. SAGE Publications Ltd., Thousand Oaks, CA, USA 303 p.

Salemink, K., Strijker, D., Bosworth, G., 2017. Rural development in the digital age: A systematic literature review on unequal ICT availability, adoption, and use in rural areas. Journal of Rural Studies 54, 360-371. https://doi.org/10.1016/j.jrurstud.2015.09.001.

Sobel, M.E., 1982. Asymptotic confidence intervals for indirect effects in structural equation models. Sociological Methodology 13, 290-312.

Spradley, J.P., 1979. The ethnographic interview. Holt, Rinehart and Winston, New York, NY, USA, 247 p.

Stephens, D.W., Krebs, J.R., 1987. Foraging theory. Princeton University Press, Princeton, NJ, USA, $247 \mathrm{p}$.

Tickamyer, A., Sherman, J., Warlick, J., 2017. Rural poverty in the United States. Columbia University Press, New York, NY, USA, 496 p.

Vaske, J., 2008. Survey research and analysis: applications in parks, recreation and human dimensions. Venture Publishing, Inc., Edmonton, Canada, 635 p.

Vaske, J., Timmons, N., Beaman, J., Petchenik, J., 2004. Chronic wasting disease in Wisconsin: hunter behavior, perceived risk, and agency trust. Human Dimensions of Wildlife 9 (3), 193-209.

Waters-Bayer, A., Bayer, W., 2016. Pastoralists in the 21st century: "Lo-Tech" meets "HiTech.". Paper presented at the 10th International Rangeland Congress, Saskatoon, Canada. Available at: http://2016canada.rangelandcongress.org/pdf/papers/X_IRC_ Proceedings_Aug2016.pdf. 